\title{
Infinite stacking of alternating polyfluoroaryl rings and bromide anions
}

\author{
V. L. Arcus, D. R. Bernstein, W. C. Crombie, G. C. Saunders \\ CrystEngComm, 2013, 15, 9841-9843
}

Requests for reprints should be made to g.saunders@waikato.ac.nz

\begin{abstract}
The crystal structure of 1-(4-bromo-2,3,5,6-tetrafluorophenyl)-3-
benzylimidazolium bromide comprises columns of parallel bromotetrafluorophenyl rings with an interplanar distance of $6.936(6) \AA$ separated by bromide anions.
\end{abstract}

The $\pi-\pi$ stacking between arenes and polyfluoroarenes is an increasingly important interaction in crystal engineering. ${ }^{1,2}$ It is expected that other electron-rich species, in particular anions, would also interact with the electron-poor polyfluoroarenes and that this interaction may also be important. A number of crystal structures do indeed possess anions positioned a short distance from the face of a polyfluoroarene (represented as $\mathrm{ArF} \cdots \mathrm{X}^{-}$), suggesting an attractive interaction, ${ }^{3}$ in particular where a polyfluoroaryl group is a component of a cation. ${ }^{4-}$ 8 These observations are supported by theroretical calculations that indicate that interactions between anions and hexafluorobenzene are attractive. ${ }^{9-11}$ For example, the energies of the optimised $\mathrm{C}_{6} \mathrm{~F}_{6} \cdots \mathrm{X}^{-}$interaction where the anion lies on the normal from the centroid were calculated (using the MP2 method and the $6-31++\mathrm{G}^{* *}$ basis set with corrections for basis set superposition and zero-point errors) to be $-76.1,-52.7$ and $-48.5 \mathrm{kJmol}^{-1}$ for fluoride, chloride and bromide respectively; the anions poisitioned at 2.570, 3.148 and $3.201 \AA$ respectively from the centroid. ${ }^{10}$ Although some of these observed structural features have been described as anion- $\square$ interactions, it has been argued that the majority of these are not genuine anion- $\square$ interactions because they do not involve neutral arenes. ${ }^{12}$ Nonetheless, whatever the exact nature of the $\operatorname{ArF} \cdots \mathrm{X}^{-}$interaction it is evident that it has potential importance in crystal engineering. ${ }^{6}$ Of particular relevance is the crystal structure of the protonated pentafluorophenylpyrromethene salt, $\left[\mathrm{C}_{6} \mathrm{~F}_{5} \mathrm{C}\left(\mathrm{C}_{4} \mathrm{H}_{3} \mathrm{NH}\right)_{2}\right]^{+} . \mathrm{Br}^{-}, 1{ }^{8}$ For each pentafluorophenyl ring there is a bromide anion positioned on one face $c a$. $3.45 \AA$ along the normal from the centroid, and another bromide anion on the other face $c a$. $3.74 \AA$ from the centroid approximately on the normal of a $\mathrm{C}-\mathrm{C}$ bond. Each bromide anion is close to two 


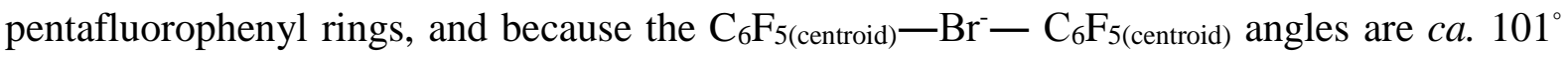
and the planes of the rings subtend an angle of $66^{\circ}$ the structure contains zigzagged chains of pentafluorophenyl rings and bromide anions. Calculations have revealed that the interaction between one bromide anion and two pentafluorophenyl rings is attractive. ${ }^{3,7}$

The calculations of $\mathrm{ArF} \cdots \mathrm{X}^{-}$interactions and the structure of $\mathbf{1}$ lead to the tantalising possibility of an infinite column of alternating polyfluoroarenes and anions analogous to columns of alternating complementary arenes and polyfluoroarenes, ${ }^{1,2}$ i.e. with parallel polyfluoroarene rings, formed by anion $-\pi$ interactions. We have previously observed the three component $\operatorname{Ar} \cdots \operatorname{ArF} \cdots \mathrm{X}^{-}$structural motif in the non-centrosymmetric crystal structure of 2,3,5,6-tetrafluoropyridyl-3-benzylimidazolium bromide, $2,{ }^{13}$ in which the bromide anion is positioned on one face of the tetrafluoropyridyl ring, 3.26(3) $\AA$ from the centroid. The other face of the tetrafluoropyridyl ring has an offset face-to-face interaction, typical of $\pi-\pi$ stacking, with the phenyl ring of another cation. That this is an energetically favourable arrangement is strongly suggested by the calculated energy of $\mathrm{C}_{6} \mathrm{H}_{6} \cdots \mathrm{C}_{6} \mathrm{~F}_{6} \cdots \mathrm{Br}^{-}$(using the MP2 method and the 6-31++ $\mathrm{G}^{* *}$ basis set with corrections for basis set superposition and zero-point errors), $67.4 \mathrm{kJmol}^{-1}{ }^{14}$ That the tetrafluoropyridyl ring in this structure undergoes interactions on both faces suggests that it may be possible for the polyfluoroaryl ring of similar cations to interact with anions on both faces. Here we report the structure of the related salt 1-(4-bromo-2,3,5,6tetrafluorophenyl)-3-benzylimidazolium bromide, 3, which contains infinite columns of alternating polyfluoroarenes and anions.

Imidazolium salt 3, prepared by treatment of 1-(4-bromo-2,3,5,6tetrafluorophenyl)imidazole ${ }^{15}$ with benzyl bromide, crystallized in the space group $P \overline{1} .^{\dagger}$ The crystal structure contains infinite columns of alternating bromide anions and bromotetrafluorophenyl rings parallel to the $a$ axis (Fig. 1). The planes of the rings are parallel and within a column are separated by $6.936(6) \AA$. They are inclined at $14.89^{\circ}$ to the plane defined by the $b$ and $c$ axes, and the columns are inclined at $83.8^{\circ}$ to the plane of the rings. The bromide anions are offset by $c a .1 .2 \AA$ from the normal of the centroids of both adjacent $\mathrm{C}_{6} \mathrm{~F}_{4} \mathrm{Br}$ rings, and lie almost on the axis of the midpoints of the $\mathrm{C}(4)-\mathrm{C}(5)$ bonds, such that the arrangement may be described as " $\eta^{2}$ " (Fig 2). ${ }^{4}$ The shortest distance of the bromide anion to the plane of one ring is 3.402(5) $\AA$. The $\mathrm{Br} \cdots \mathrm{C}(4)$ and $\mathrm{Br} \cdots \mathrm{C}(5)$ distances to this ring are 3.521(5) and 3.434(4) A respectively. The shortest distance of the bromide anion to the plane of the other ring is 3.534(5) $\AA$. The $\mathrm{Br} \cdots \mathrm{C}(4)$ and $\mathrm{Br} \cdots \mathrm{C}(5)$ distances to this ring are 3.571(4) and 3.723(5) A respectively. The distances to the centroids are 3.626(5) and 3.888(5) $\AA$. All 
these distances are less than the sum of the van der Waals radius of carbon $(1.70 \AA)^{15}$ and the corrected van der Waals radius of the bromide anion $(2.35 \AA)$, and so fall well within the criterion for an anion $-\pi$ interaction $(\leq \Sigma \mathrm{vdW}$ radii $+0.4 \AA) .{ }^{11} \mathrm{MP} 2$ calculations on the energy of interaction between hexafluorobenzene and chloride have revealed that there is a shallow minimum along all three axes of displacement of the anion from the ring centroid: the magnitude of the interaction energy decreases only slightly on displacement of the anion away from the normal to the ring centroid to the ring edge (by ca. 10\%), and on increasing the distance by $0.7 \AA$ from the centroid along the normal (by ca. 20\%). ${ }^{11}$ Thus, it is concluded that there are attractive interactions between the bromide anion and both rings in the crystal structure of $\mathbf{3}$.

The geometry about $\mathrm{C} 1$ and the short $\mathrm{C} 1 \cdots \mathrm{Br}$ distance (3.350(4) $\mathrm{A}$ ) suggests a degree of hydrogen bonding between the anion and the most acidic hydrogen atom of the imidazolium ring bonded to the more distant ring (Fig. 3). ${ }^{17}$ In addition to this interaction, and those with the faces of the two rings, the bromide anion also interacts with the covalently bonded bromine atom of a third cation. The $\mathrm{Br} \cdots \mathrm{Br}^{-}$distance of 3.2670(6) $\AA$ and the $\mathrm{C}-\mathrm{Br} \cdots \mathrm{Br}^{-}$angle of $177.4(1)^{\circ}$ are consistent with halogen bonding between bromide and bromine. ${ }^{18}$ The interaction of bromide with covalently bonded bromine in small organic molecules has been calculated to be attractive by between 1 and $29 \mathrm{kJmol}^{-1}{ }^{18}$ The interaction leads to the columns being arranged in pairs with the $\mathrm{C}-\mathrm{Br}$ bonds of one column almost overlapping those of its partner in a head-to-tail manner (Fig 4). The distances between adjacent covalently bonded bromine atoms are 3.7079(6) and 3.8753(7) $\AA$.

That the crystal structure of $\mathbf{2}$ displays $\pi-\pi$ stacking between aryl and polyfluoroaryl groups $^{13}$ and that of $\mathbf{3}$ doesn't may be because of two factors. Firstly, the combination of $\mathrm{ArF} \cdots \mathrm{Br}^{-}$and $\mathrm{Br}^{\cdots} \mathrm{Br}^{-}$interactions expressed by 3 may be stronger than the $\mathrm{Ar} \cdots \mathrm{ArF} \cdots \mathrm{Br}^{-}$ interactions. Secondly, that if $\pi-\pi$ stacking were to occur the extra steric requirement of the covalently bonded bromine atom of $\mathbf{2}$ may preclude other favourable interactions.

The crystal structure of $\mathbf{3}$ contains parallel columns of alternating bromotetrafluorophenyl rings and bromide anions. The rings are parallel and the bromide anions are offset by ca. $1.2 \AA$ from the normal of the centroids of the rings. The relatively short distances of the anions to the planes, when compared to the results of previously reported theoretical calculations performed on related systems, ${ }^{9-11}$ suggests that there is a significant attractive interaction between an anion and both adjacent rings. 
Acknowledgement: We thank Prof B. K. Nicholson for his assistance in collecting the X-ray data.

1 A. Hori in, The Importance of Pi-Interactions in Crystal Engineering: Frontiers in Crystal Engineering, ed. E. R. T. Tiekink and J. Zukerman-Schpector, J. Wiley \& Sons, Ltd., Chichester, 2012, chap. 7, pp. 163-185.

2 For example: A. R. Dunn, L. M. Dougherty and R. A. Grubbs, Angew. Chem., Int. Ed. Engl., 1997, 36, 248; C. E. Smith, P. S. Smith, R. Ll. Thomas, E. G. Robins, J. C. Collings, C. Dai, A. J. Scott, S. Borwick, A. S. Batsanov, S. W. Watt, S. J. Clark, C. Viney, J. A. K. Howard, W. Clegg and T. B. Marder, J. Mater. Chem., 2004, 14, 413; J. C. Collings, P. S. Smith, D. S. Yufit, A. S. Batsanov, J. A. K. Howard and T. B. Marder, CrystEngComm, 2004, 6, 25; J. M. Serrano-Becerra, S. Hernández-Ortega, D. Morales-Morales and J. Valdés-Martínez, CrystEngComm, 2009, 11, 226; J. R. Lane, G. C. Saunders and S. J. Webb, CrystEngComm, 2013, 15, 1293; T. Itoh, M. Kondo, M. Kanaikea and S. Masaoka, CrystEngComm, 2013, 15,6122 .

3 M. Giese, M. Albrecht, T. Krappitz, M. Peters, V. Gossen, G. Raabe, A. Valkonen and K. Rissanen, Chem. Commun., 2012, 48, 9983.

4 M. Albrecht, M. Müller, O. Melgel, K. Rissanen and A. Valkonen, Chem. Eur. J., 2010, 16, 5062 ;

5 M. Giese, M. Albrecht, C. Bannwarth, G. Raabe, A. Valkonen and K. Rissanen, Chem. Commun., 2011, 47, 8542.

6 M. Giese, M. Albrecht, K. Wiemer, A. Valkonen and K. Rissanen, New J. Chem., 2012, 36, 1368 .

7 M. Albrecht, C. Wessel, M. de Groot, K. Rissanen and A. Lüchow, J. Am. Chem. Soc., 2008, 130, 4600 .

8 J.-Y. Shin, D. Dolphin and B. O. Patrick, Cryst. Grow. Des., 2004, 4, 659.

9 I. Alkorta, I. Rozas and J. Elguero, J. Am. Chem. Soc., 2002, 124, 8593; D. Quiñonero, C. Garau, C. Rotger, A. Frontera, P. Ballester, A. Costa and P. M. Deyà, Angew. Chem., Int. Ed., 2002, 41, 3389.

10 A. Frontera, P. Gamez, M. Mascal, T. J. Mooibroek and J. Reedijk, Angew. Chem., Int. Ed., $2011, \mathbf{5 0}, 9564$.

11 C. Estarellas, A. Bauzá, A. Frontera, D. Quiñonero and P. M. Deyà, Phys. Chem. Chem. Phys., 2011, 13, 5696.

12 B. P. Hay and R. Custelcean, Cryst. Growth Des., 2009, 9, 2539. 
13 G. C. Saunders, CrystEngComm, 2011, 13, 1801.

14 A. Frontera, D. Quiñonero, A. Costa, P. Ballester and P. M. Deyà, New J. Chem., 2007, 31, 556.

15 S. Fujii, Y. Maki and H. Kimoto, J. Fluor. Chem., 1989, 43, 131.

16 A. Bondi, J. Phys. Chem., 1964, 68, 441; R. S. Rowland and R. Taylor, J. Phys. Chem., 1996, 100, 7384.

17 G. R. Desiraju, Angew. Chem., Int. Ed., 2011, 50, 52.

18 S. V. Rosokha, C. L. Stern and J. T. Ritzert, Chem. Eur. J., 2013, 19, 8774.

19 G.M. Sheldrick, SHELXS-97-A Program for the Solution of Crystal Structures, University of Göttingen, Germany, 1997.

20 G.M. Sheldrick, SHELXL-97-A Program for the Refinement of Crystal Structures, University of Göttingen, Germany, 1997.

$\dagger$ CCDC 954990. Crystallographic data for 3 (colourless brick): $\mathrm{C}_{16} \mathrm{H}_{10} \mathrm{Br}_{2} \mathrm{~F}_{4} \mathrm{~N} 2, \mathrm{M}$ 466.08, triclinic, $P \overline{1}, a=6.9774(2), b=10.7434(5), c=11.8115(4) \AA, \alpha=103.704(3), \beta=$ 102.664(3), $\gamma=103.066(3)^{\circ}, V=802.36(5) \AA^{3}, Z=2, D_{\text {calc }}=1.929 \mathrm{gcm}^{-3}, \mu(\mathrm{Cu} \mathrm{K \alpha}) 6.826$ $\mathrm{mm}^{-1}$, crystal size $0.63 \times 0.20 \times 0.20 \mathrm{~mm}$. Data were collected at $100(2) \mathrm{K}$ on an Agilent supernova diffractometer using $\mathrm{Cu} \mathrm{K} \alpha$ radiation. A total of 7096 reflections $(4.02<\theta<$ $\left.73.31^{\circ}\right)$ were collected, of which 3038 were unique with $I>2 \sigma(I)$. The structure was solved by direct methods using SHELXS- $97^{19}$ and refined using SHELXL-9720 with all non-H atoms anisotropic. $R_{\text {int }}=0.0303, R_{1}=0.0450, w R_{2}=0.1473$, GOF $=1.147$.

Figure 1:

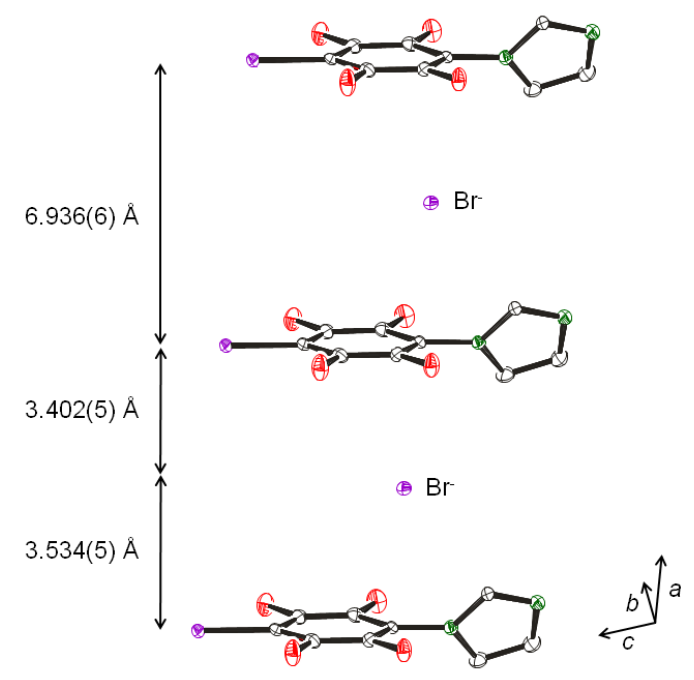


Figure 2:

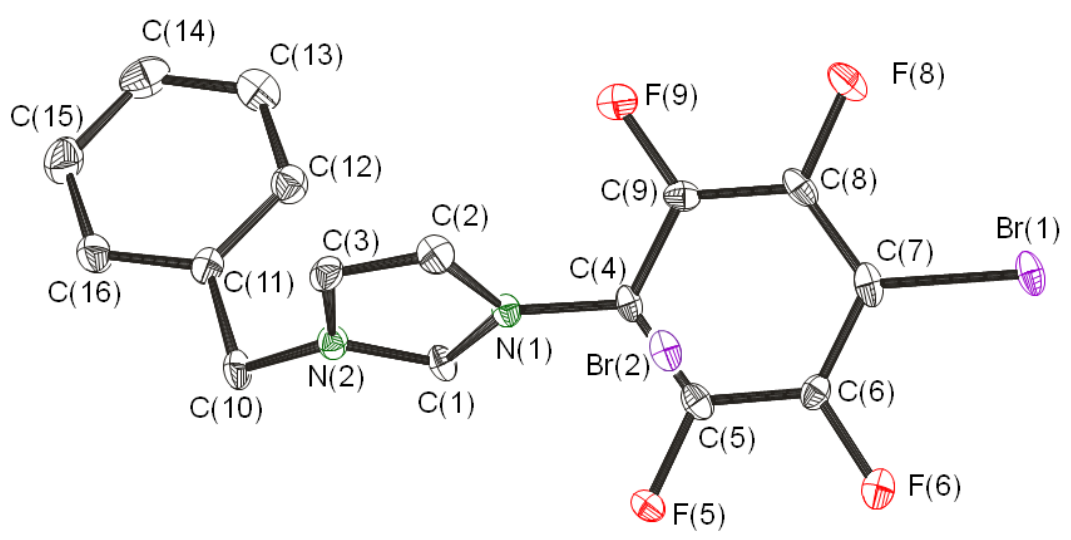

Figure 3:

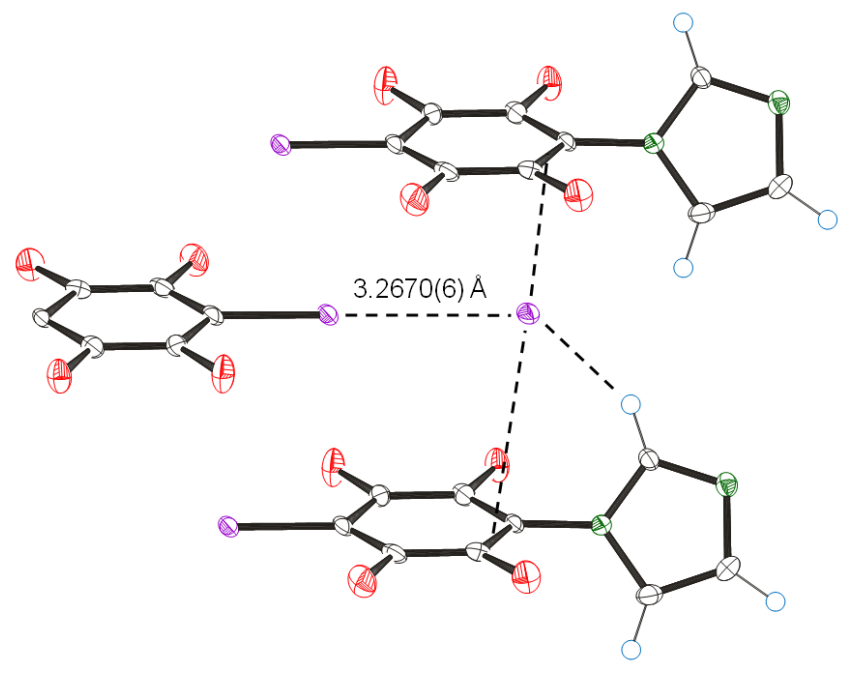

Figure 4:

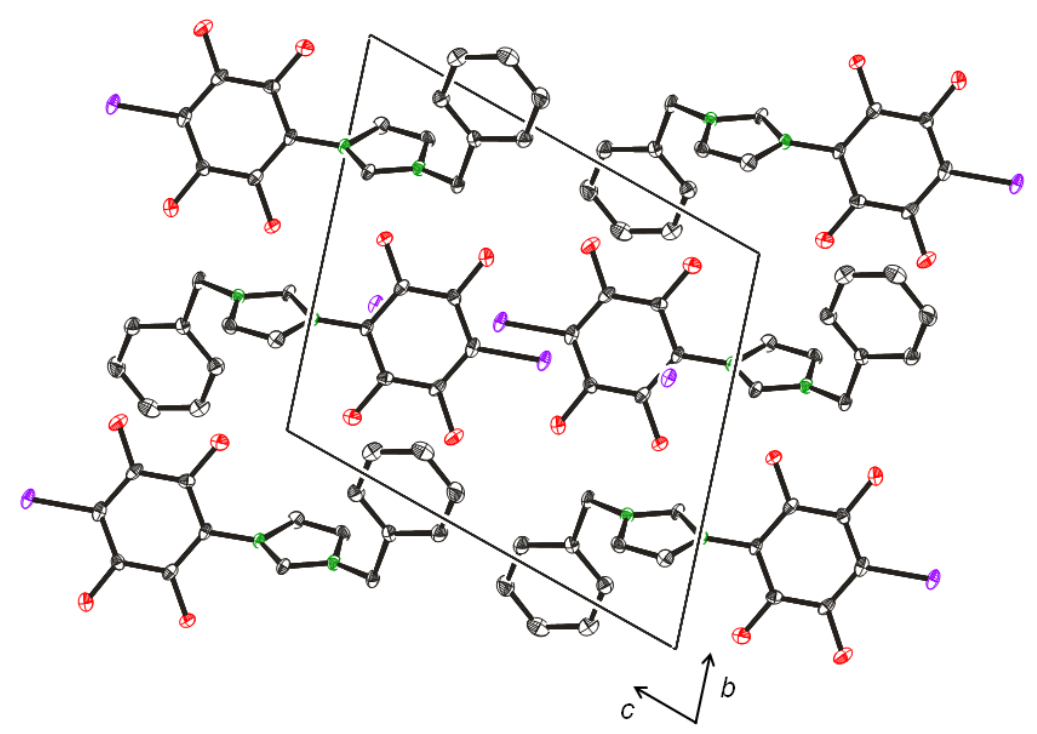

